\title{
Safety of Frozen Shrimp Imported through Entry Points in Selangor, Malaysia
}

\author{
Jeyaletchumi P, Hekambaram M, Azhar A, Param J.S.P.S, Ghani,A.A.S, Harliani R, Rafidah I
}

\begin{abstract}
The presence of antibiotic residues in food raises significant public health concerns as it may result in increased antimicrobial resistance in human pathogens. Recently the United States of America issued an import alert on shrimp from Peninsular Malaysia after detecting illegal and unsafe levels of drug residues in thirty two percent of samples tested over a oneyear period. As local investigations at aquaculture farms could not detect drug residues at farm level, transshipment of imported prawns was suspected. The Food Safety and Quality Department of the Selangor State Health Department, Port Klang Health Office, Selangor Food Safety and Quality Laboratory and National Public Health Laboratory conducted a study to assess the safety of imported shrimps through sampling at entry points through which frozen prawns are actively imported. Analysis of nitrofuran, chloramphenicol, malachite green and crystal-violet were carried out through Liquid Chromatography Mass Spectrometry at two Laboratories on one hundred and forty seven samples taken over a four month period but none were found to contain drug residues. The results which indicate a total absence of drug residues in frozen shrimp from the region are reassuring but somewhat surprising and suggest the use of analytical methods with a higher sensitivity.
\end{abstract}

\section{Index Terms : entry points, safety, Selangor, shrimp}

\section{INTRODUCTION}

Recently the Malaysian seafood industry has been questioned with regards to the safety of shrimp exported to the United States of America (US) [1]-[2]. In a study that ran from Oct. 1, 2014, to Sept. 30, 2015, FDA found the antibiotic residues in 45 samples or about 32 percent of the shrimp and prawns being exported to the U.S. from Peninsular Malaysia [3] -[5].

During investigations at aquaculture farms, the Ministry of Agriculture of Malaysia could not detect drug residues at farm level and also had difficulty in accounting for the high volumes of shrimp exported to the United States from Malaysia. Malaysia itself imports a large quantity of prawns for domestic use from China, India, Vietnam, Indonesia, Thailand and Pakistan. Therefore, it was suggested that transshipment, which refers to products being imported into the country, illegally relabeled as originating from Malaysia

Jeyaletchumi P, Sabah State Health Department, Ministry of Health, Malaysia.(E-Mail:jeyaletchumi@moh.gov.my)

Hekambaram M, Selangor State Health Department, Ministry of Health, Malaysia.(E-Mail:hekam@moh.gov.my)

Azhar A, Selangor State Health Department, Ministry of Health, Malaysia.(E-Mail:azhar@moh.gov.my)

Param J.S.P.S, Port Klang Health Office, Ministry of Health, Malaysia.(E-Mail:param@moh.gov.my)

Ghani,A.A.S, National Public Health Laboratory, Ministry of Health, Malaysia.(E-Mail:abdulghani@moh.gov.my)

Harliani R, Selangor Food Safety and Quality Laboratory, Ministry of Health, Malaysia.(E-Mail:harliani@moh.gov.my)

Rafidah I, Selangor Food Safety and Quality Laboratory, Ministry of Health, Malaysia.(E-Mail:afidahmkak@moh.gov.my)
Revised Manuscript Received on September 10, 2019.

and reexported as Malaysian products to the United States could be the root of the problem.

The use of unapproved antibiotics or chemicals in aquaculture raises significant public health concerns as the presence of antibiotic residues may contribute to an increase of antimicrobial resistance in human pathogens. Moreover, prolonged exposure to chloramphenicol, nitrofuran, malachite green, and gentian violet have been shown to have a carcinogenic affect [5].

While none of the exporting factories involved in rejections were based in the state of Selangor, this issue has nonetheless raised some doubt on the safety of imported shrimp consumed domestically. After all, if tainted shrimp products are exported to the United States which practices such stringent control on imported foods and is able to detect veterinary drug residues in shrimp products originating from the Asian region, this implies rampant abuse of veterinary drugs in the region and drug residues would be expected to be found through random sampling in frozen shrimp exported to Malaysia from Asian countries.

Therefore, the Food Safety \& Quality Department of the Selangor State Health Department with the cooperation of Port Klang Health Office, Selangor Food Safety \& Quality Laboratory and National Public Health Laboratory conducted a study to assess the safety of imported shrimps in terms of drug residue contamination. This is an original research project that had not been carried out previously. In terms of feasibility, sampling was carried out at the 2 entry points through which frozen prawns are actively imported i.e. North Port and West Port of the Port Klang sea port of entry. The Selangor Food Safety \& Quality Laboratory and the National Public Health Laboratory have the capability of carrying out analysis of nitrofuran, chloramphenicol, malachite green as well as crystal-violet which have been detected in consignments sent to the United States prior to rejection.

The general objective of this research was to assess safety of frozen prawns imported through entry points in Selangor in terms of drug residue contamination. The specific objectives of this research was to assess the frozen prawns imported through entry points in Selangor for the presence of specific drug residues such as chloramphenicol, nitrofuran, malachite green and crystal violet. It also aimed to determine prevalence and levels of drug residue contamination in frozen prawns imported through entry points in Selangor as well as determine the origin of contaminated prawns so more stringent measures could be put in place when importing from these countries. 


\section{MATERIAL AND METHODOLOGY}

Sampling was carried out at the 2 entry points which receive frozen prawns i.e. North Port and West Port by officers from the Port Klang Health Office over a 4 month period in 2016 wherein consignments that come during this period was randomly sampled and sent for chemical analysis. The cold chain was maintained throughout sampling and transportation. Drug residue analysis was carried out at the Selangor Food Safety \& Quality Laboratory and National Public Health Laboratory.

Analysis was carried out at the laboratories using three methods that are accredited under the ISO/ IEC 17025. For chloramphenicol and nitrofuran analysis, extraction was carried out using ethyl acetete followed by centrifugation. Purification was carried out through Solid Phase Extraction using OASIS HLP SPE column for chloramphenicol and octadecyl column for nitrofuran. For chloramphenicol, determination of amphenicol in animal tissues by Ultra Performance Liquid Chrmoatography Tandem Mass Spectrometry [6]-[9].

For nitrofuran, determination of nitrofuran metabolites residues in fish and fish products by Liquid Chromatography Tandem Mass Spectrometry was carried out [10-11]. For malachite green and crystal violet,the homogenized sample was extracted with hydroxylamine solution, acetonitirle and magnesium sulphate. Determination of triphenylmethane dyes was done using the method for solvent extraction in fish and fish products by Liquid Chromatography Tandem Mass Spectrometry [12].

Quantification of chloramphenicol, nitrofuran, malachite green and gentian violet was done by Liquid Chromatography Tandem Mass Spectrometry with Multi Residue Monitoring and Electron Spray Ionization.

\section{RESULTS AND DISCUSSION}

One hundred and forty seven samples were taken over a four month period in 2016 from forty two consignments originating from six countries that actively export shrimp products to Malaysia but none of the samples were found to contain drug residues. Samples comprised Vannamei shrimp, frozen scampi, frozen shrimp and frozen prawns that had been obtained from India, China, Indonesia, Thailand, Pakistan and Vietnam. Table 1 states the type of parameters tested and number of samples for each parameter while Table 2 states the quantity of consignments from the country of origin during the sampling period.

The results are somewhat surprising and appear to contradict assumptions that prawns from the Asian region are contaminated with veterinary drug residues. At the same time, the total absence of drug residues in products that originate from countries that are banned from exporting shrimp to the United States or have a history of violations cast some doubt on the the detection methods employed. The FSIS cut-off point for chloramphenicol in shrimp is 0.3 parts per billion whereas the Limit of Quantification for chloramphenicol at the Selangor Food Safety \& Quality Laboratory is 0.2 parts per billion therefore if chloramphenicol had been used, they should have been detected. However the analytical parameters that had been methodology employed was based on the procedure for

tested were limited to four parameters and the equipment used in the laboratory may not be as sophisticated as that used in the U.S. and this could have contributed to the failure to detect any contraventions.

It is suggested that analytical methods similar to that employed by the USFDA be used at the laboratories under the Ministry of Health. Another possibility is that the shrimp importers were aware of heightened inspection and sampling at the ports of entry as sampling is carried out in their presence and may have informed the agents of the various countries on the strict sampling carried out and this may have influenced the quality of products being sent during this period.

Rejection of consignments by foreign buyers is a major concern to the export sector. The USFDA has requested that the Malaysian government conduct an investigation into the residue problem and ultimately develop short term and long term measures to address the problem and prevent the export of adulterated shrimp. The findings of the study seem to indicate that close surveillance and sampling must be carried out on all shrimp products exported and imported using methods and equipment with a higher sensitivity.

The United States regulations with regards to permissible levels of drug residues in food are also slightly inconsistent in that for meat, the FSIS regulatory cut-off point for chloramphenicol is $3 \mathrm{ppm}$ which is almost 10 times more than that allowed for shrimp which is inexplicable as the consumption of meat would undoubtedly be higher in the daily diet of the population. It is suggested that uniform cutoff points be set for drug residues if the intention is truly to protect the consumer.

\section{ACKNOWLEDGEMENT}

The Food Safety \& Quality Division of the Selangor State Health Department would like to thank all the personnel from the Import \& Export Section, Food Safety \& Quality Division of the Selangor State Health Department, Port Klang Health Office, Klang Food Safety \& Quality Laboratory and Sungei Buloh Public Health Laboratory who were directly and indirectly involved in this study. We would also like to thank the Food Safety \& Quality Division of the Ministry of Health Malaysia for providing the financial grant to do this study and the Director General of the Ministry of Health for granting permission to publish the findings of the study.

\section{REFERENCES}

1. www. seafoodnews.com. Refusal of Malaysian Shrimp due to Harmful and Illegal Drugs

2. http://www.foodsafetynews.com: Barriers go up against shrimp and prawns from Malaysia.

3. https://www.accessdata.fda.gov .USFDA Import Refusal Report

4. www.shrimpalliance.com. FDA Refusal of Shrimp Entry Lines Contaminated by Banned Antibiotics.

5. https://www.consumer.org.my: Government must stop use of antibiotics in our shrimp 
6. Food Safety and Quality Laboratory, Ministry of Health Malaysia, "In-house Method :Determination of Amphenicols in Animal Tissue by Ultra Performance Liquid Chromatography Tandem Mass Spectrometry", 2013.

7. Antoinetta,G.,Gordon,K., John H, Lynne C.C., Paul,B., "Determination of Chlorampehicol using acquity UPLC and Quattro Premier Xe in ES Negative Ion Mode MSMS", Applicatin Note.Waters Corporation, 2013

8. Hancock,P. , "Confirmatory Method for the determination of chloramphenicol, thiamphenicol and florfenicol in honey" , Application Notes; Waters Corporation, Atlas Park,2013.

9. Nollet,L.M.L.; Toldora.F., "Handbook of Muscle Food Analysis", pp.233-244,Boca Raton Press,2009

10. Food Safety and Quality Laboratory, Ministry of Health Malaysia. "In-house Method : Determination Of Nitrofuran Metabolite Residues in Meat and Meat Products and Fish and Fish products by Liquid Chromatography Tandem Mass Spectrometry”,2013.

11. Leitner, A., Zollner,P. and Lidner,W. "Determination of the metabolites of nitrofuran antibiotics in animal tissues by High Performance Liquid Chromatography-tandem mass spectrometry" Journal of Chromatography A 939,no.1:49-58, 2001

12. Food Safety and Quality Laboratory, Ministry of Health Malaysia. "In-house Method : Determination of Triphenylmethane Dyes by Solvent Extraction in Fish \& Fish products by Liquid Chromatography Tandem Mass Spectrometry", 2014.

Table 1: Types of parameters and number of samples

\begin{tabular}{|l|c|l|}
\hline \multicolumn{1}{|c|}{ Parameter } & No.of samples & Results \\
\hline Chloramphenicol & 42 & Negative \\
\hline Nitrofuran & 36 & Negative \\
\hline Malachite Green & 28 & Negative \\
\hline Crystal Violet & 41 & Negative \\
\hline
\end{tabular}

Table 2: Country of origin of prawn consignments taken for study

\begin{tabular}{|c|c|}
\hline Country & No.of consignments \\
\hline China & 18 \\
\hline India & 9 \\
\hline Indonesia & 8 \\
\hline Vietnam & 4 \\
\hline Thailand & 2 \\
\hline Australia & 1 \\
\hline Total & 42 \\
\hline
\end{tabular}

